\title{
Preparation of a transparent and flexible self-standing film of layered titania/isostearate nanocomposite
}

\author{
Taki Matsumoto, ${ }^{\text {a) }}$ Nobuo Iyi, Yoshiro Kaneko, and Kenji Kitamura \\ Advanced Materials Laboratory, National Institute for Materials Science (NIMS), \\ Tsukuba 305-0044, Japan \\ Satoru Masaki, Tomohito Imai, Wataru Sugimoto, Yoshio Takasu, and Yasushi Murakami \\ Department of Fine Materials Engineering, Faculty of Textile Science and Technology, \\ Shinshu University, Ueda 386-8567, Japan
}

(Received 19 August 2004; accepted 15 February 2005)

A titania-based self-standing film with high transparency and flexibility was successfully prepared via a sol-gel process, in which a titanium tetraisopropoxide/ isostearate complex (precursor), $n$-hexylammonium isostearate (catalyst), and $o$-xylene (solvent) were used. The sol obtained by the sol-gel reaction was floated on a water surface to form an unsupported film. This film was composed of a titania/isostearate nanocomposite with ordered layer structure. The basal spacings of the nanocomposites depended on the chain length of the carboxylate modifier.

\section{INTRODUCTION}

Recently, the preparation of inorganic/organic nanocomposites by the sol-gel process has been intensively investigated. ${ }^{1-3}$ Of the various inorganic/organic nanocomposites, layered nanocomposites consisting of stacked oxide sheets belong to one of the most important material systems because these materials have potential applicability as adsorbents, catalysts, and hosts for various guest molecules. So far, a large number of papers have been published on the synthesis of silica-based layered nanocomposites obtained by the sol-gel reaction of silicon alkoxide in the presence of surfactants forming micelle templates. ${ }^{4-7}$

Processing these materials into thin films is another important subject, especially from a technological point of view. A large number of papers have reported the synthesis of supported films of nanocomposites, ${ }^{5-8}$ however, the films required for practical application are unsupported ones. Self-standing films would find wide application, such as catalyst supports and separation membranes, for which supported films are not suitable. The preparation of transparent self-standing films of silicabased nanostructured materials was already reported by Ogawa and his co-workers. ${ }^{9,10}$ They prepared transparent films of layered silica/surfactant nanocomposites from tetramethoxysilane and obtained self-standing films by peeling the dried films off a polyethylene substrate. ${ }^{9}$

\footnotetext{
a) Address all correspondence to this author. e-mail: MATSUMOTO.Taki@nims.go.jp DOI: $10.1557 / J M R .2005 .0165$
}

They also prepared thin films of the silica/surfactant mesostructured materials by removing the films from PMMA-coated glass substrates by dissolving the intervening [poly(methyl methylacrylate)] (PMMA). ${ }^{10}$ In these works on the synthesis of silica-based nanocomposite films, silica/alkyltrimethylammonium complexes were assembled by the hydrophobic interaction between the long alkyl chains in aqueous solution, and an ordered structure was constructed on the substrate by condensation due to the evaporation of the solvent. ${ }^{7,8}$

The preparation and characterization of titania $\left(\mathrm{TiO}_{2}\right)$ is one of the subjects of current research because of its excellent photo-semiconducting property, and in particular, highly transparent titania are strongly desired. ${ }^{11}$ If the titania-based oxide materials can be obtained in a layered form, they could be used as the precursor for new types of photofunctional materials due to their highly ordered structure and to a large interlayer area suitable for the incorporation of other photofunctional guests. However, transparent self-standing films of layered titania/organic nanocomposites have not been obtained by similar methods for preparing silica/organic nanocomposite films. These difficulties come from the reactivity of titanium alkoxide, which is much higher than that of silicon alkoxide. ${ }^{3,12,13}$ The hydrolysis rate of titanium alkoxide is much faster than that of silicon alkoxide. With the coexistence of surfactants such as alkyltrimethylammonium ion, layered silica is obtained by two-dimensional growth in aqueous solution; in contrast, spherical particles of titanium oxide are usually obtained from titanium alkoxide in the same aqueous environment. ${ }^{14}$ Ogawa et al. ${ }^{15}$ reported the synthesis of a transparent self-standing film of nanoporous silica containing titanium oxide; however, 
it was basically composed of silica because the $\mathrm{Ti} / \mathrm{Si}$ ratio was quite low $(\mathrm{Ti} / \mathrm{Si}=1 / 50)$. Xu and Anderson ${ }^{16}$ prepared unsupported titania membranes via the sol-gel reaction of titanium tetra-tert-amyloxide. These membranes were obtained by firing a xerogel consisting of small colloidal particles (less than $3 \mathrm{~nm}$ in diameter) and cannot be classified as inorganic/organic nanocomposites. These membranes did not have an ordered layer structure, but instead they had a microporous structure formed by the packing of fine particles. Moriguch et al. ${ }^{17,18}$ obtained a $\mathrm{TiO}_{2}$ nanoparticulate film on various substrates such as a quartz plate and a $\mathrm{Si}$ wafer by the Langmuir-Blodgett method, though the material thus obtained was not self-standing.

Deceleration of the hydrolysis of titanium alkoxide is necessary for the synthesis of layered titanium oxide because the dimension of polymerization in the sol-gel process depends on the rate of hydrolysis. ${ }^{19}$ Without the deceleration of the hydrolysis, three-dimensional polymerization takes place due to very rapid hydrolysis of the titanium alkoxides. For the formation of layered materials, two-dimensional polymerization is required.

Only decelerated hydrolysis leads to the formation of small colloidal particles with the development of a titanium oxide network. ${ }^{16}$ Appropriate two-dimensional growth does not occur because the polycondensation rate of titanium alkoxide is significantly slow. ${ }^{20}$ The reactive sites for polycondensation are hydroxy groups formed by the hydrolysis of titanium alkoxide, so polycondensation would be decelerated by slow hydrolysis. Therefore, not only the deceleration of the hydrolysis but also the acceleration of the polycondensation is indispensable for forming an ordered layer structure.

In this paper, we report the synthesis of a layered titania/isostearate nanocomposite with the simultaneous controlling of the hydrolysis and polycondensation. For decelerating hydrolysis, a hydrophobic organic solvent, $o$-xylene, was used. The hydrolysis of metal alkoxides is retarded in hydrophobic solvents. ${ }^{21}$ On the other hand, for accelerating polycondensation, $n$-hexylammonium isostearate salt was used as a catalyst. We have already found that the salt catalyst effectively accelerates the polycondensation of titanium alkoxide. ${ }^{19,20,22,23} \mathrm{We}$ also report the unique procedure for making a self-standing film of layered titania/isostearate nanocomposite by floating the sol on the water surface, which yields selfstanding films with good transparency and flexibility.

\section{EXPERIMENTAL}

\section{A. Materials and sample preparations}

Titanium tetraisopropoxide ( $>97 \%$, Kanto Chemical Co., Inc., Tokyo, Japan), isostearic acid (>95\%, Tokyo Kasei Kogyo Co., Ltd., Tokyo, Japan), $n$-octanoic acid (>98\%, Tokyo Kasei Kogyo Co., Ltd., Tokyo, Japan), $n$-hexanoic acid (>98\%, Tokyo Kasei Kogyo Co., Ltd., Tokyo, Japan), $n$-butyric acid (>99\%, Tokyo Kasei Kogyo Co., Ltd., Tokyo, Japan), $n$-hexylamine ( $>98 \%$, Tokyo Kasei Kogyo Co., Ltd., Tokyo, Japan), and $o$-xylene (>99\%, Kanto Chemical Co., Inc., Tokyo, Japan) were used without further purification.

The typical experimental procedure is as follows.

Two $o$-xylene solutions were prepared under nitrogen atmosphere. One contained $12.5 \mathrm{mmol}$ titanium tetraisopropoxide $\mathrm{Ti}\left[\mathrm{OCH}\left(\mathrm{CH}_{3}\right)_{2}\right]_{4}$ and $6.25 \mathrm{mmol}$ isostearic acid $\left\{\mathrm{CH}_{3}\left(\mathrm{CH}_{2}\right)_{8}-\mathrm{CH}\left[\left(\mathrm{CH}_{2}\right)_{6} \mathrm{CH}_{3}\right]-\mathrm{COOH}\right\}$ in $15 \mathrm{ml} o-$ xylene, and the other contained $1.25 \mathrm{mmol}$ isostearic acid and $1.25 \mathrm{mmol} n$-hexylamine in $10 \mathrm{ml} o$-xylene. The sol-gel reaction was started by mixing both solutions together. Hydrous nitrogen gas $(300 \mathrm{ppm}$ in moisture content) was used to add the water required for the solgel reaction. The reactor was kept under the bubbling hydrous nitrogen gas with a $2.5 \mathrm{ml} \mathrm{min}^{-1}$ flow rate to gradually absorb moisture from the gas for $180 \mathrm{~h}$. The reaction temperature was $25^{\circ} \mathrm{C}$. The sol obtained by this reaction was floated on the water. After floating the sol on the water surface for $2 \mathrm{~h}$, the floating film was pulled up and dried at $80{ }^{\circ} \mathrm{C}$.

\section{B. Characterization techniques}

Infrared absorption spectra of solutions were obtained with a Perkin-Elmer 1650FTIR (Boston, MA) spectrometer by the transmission method. The reaction process was monitored by measuring the solution viscosity (Viscomate VM-1A-L, Yamaichi Electronic Co. Ltd., Tokyo, Japan). The obtained sols and precipitates were diluted with a solvent and dropped on smooth plates of a cleaved, highly oriented pyrolytic graphite and dried under vacuum for $5 \mathrm{~h}$. Their morphology was observed with a scanning electron microscope (SEM, S-500, Hitachi, Ltd., Tokyo, Japan). Samples (sol or film) for x-ray diffraction (XRD; RINT2550H, Rigaku Co. Ltd., Tokyo, Japan) were cast on a glass plate and dried at $80{ }^{\circ} \mathrm{C}$. The ultraviolet-visible (UV-vis) absorption spectrum of the resultant film was obtained using a spectrometer (UV2400PC, Shimadzu Corporation, Kyoto, Japan). The dried film was ground to powder and dispersed with methanol for the observation with a transmission electron microscope (TEM; JEM1010, JEOL Ltd., Tokyo, Japan).

\section{RESULTS AND DISCUSSION}

\section{A. Formation of isostearate-modified titanium alkoxide and a salt catalyst}

In the solution containing a mixture of $\operatorname{Ti}\left[\mathrm{OCH}\left(\mathrm{CH}_{3}\right)_{2}\right]_{4}$ and isostearic acid, isostearate-modified titanium alkoxide was readily formed. The infrared (IR) spectra of the mixture [Fig. 1(B)] showed characteristic absorption bands at 1427,1460 , and $1542 \mathrm{~cm}^{-1}$, which were attributed to the $\mathrm{COO}^{-}$stretching for bidentate coordination of 


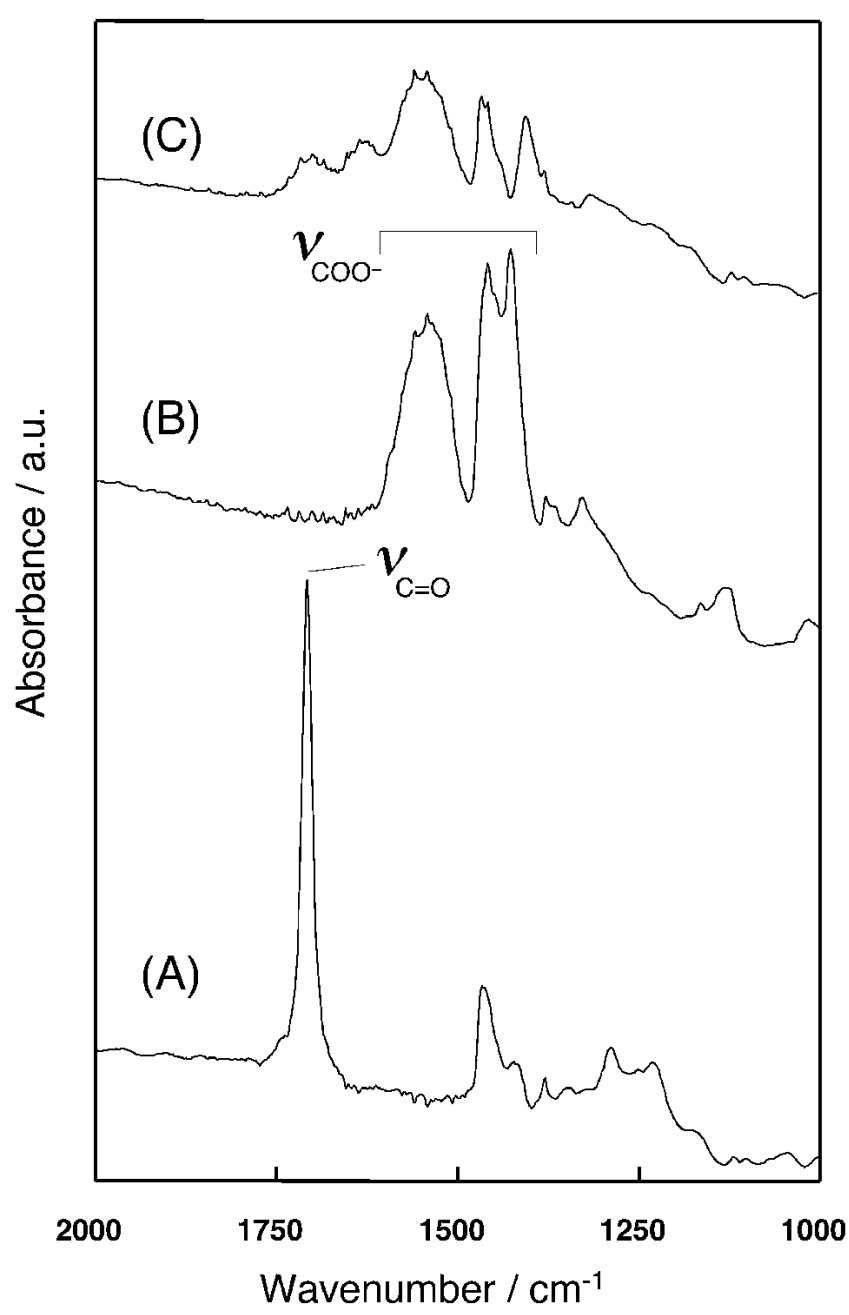

FIG. 1. IR absorption spectra of $o$-xylene solution containing (A) isostearic acid, (B) a mixture of isostearic acid and titanium alkoxide, and (C) a mixture of isostearic acid and $n$-hexylamine.

the Ti(IV)-carboxylate complex. ${ }^{19}$ An absorption band at $1707 \mathrm{~cm}^{-1}$ assigned to the $\mathrm{C}=\mathrm{O}$ stretching for isostearic acid [Fig. 1(A)] was not observed. Isostearate-modified titanium alkoxide could be easily dispersed in $o$-xylene because isostearate has an organophilic long alkyl chain. ${ }^{22}$

In the $o$-xylene solution of a mixture of isostearic acid and $n$-hexylamine, $n$-hexylammonium isostearate salt formed. As shown in Fig. 1(C), the absorption band at 1707 $\mathrm{cm}^{-1}$ attributable to isostearic acid [Fig. 1(A)] disappeared due to the neutralization of isostearic acid by $n$-hexylamine.

\section{B. Formation of titania/isostearate nanocomposite in a hydrophobic solvent with a salt catalyst}

Titania/isostearate nanocomposites were prepared via a sol-gel process from isostearate-modified titanium alkoxide in a hydrophobic solvent (o-xylene). The water required for the hydrolysis of the sol-gel reaction was successively added by continuous bubbling of the hydrous nitrogen gas. Because of the hydrophobicity of the solvent and the gradual water addition procedure, the water content of the reaction system was kept very low. Although such a condition is suitable for the control of the hydrolysis reaction, slow reaction rate caused by the low-water content can be a problem. To overcome this problem, hexylammonium isostearate was used as a salt catalyst to accelerate polycondensation.

Viscous clear sol was formed by the sol-gel reaction with an increase in the solution viscosity, as shown in Fig. 2(A). This indicates that the well-grown titania product would be formed in the solution. Characteristic IR absorption bands at 1428 and $1533 \mathrm{~cm}^{-1}$ were observed for the sol after drying at $120{ }^{\circ} \mathrm{C}$. These bands were attributed to the $\mathrm{COO}^{-}$stretching of the titania/ carboxylate complex. ${ }^{19}$ Isostearate modifiers still remained and were bonded to the final titania product; that is, the titania/isostearate composite was formed. Sanchez and Ribot ${ }^{3}$ indicated that for low water content $\left(\left[\mathrm{H}_{2} \mathrm{O}\right] /\right.$ $[\mathrm{Ti}] \ll 1$ ) acetylacetonate (acac) modified titanium alkoxide led to modified oxo-alkoxide clusters. Here acacmodifiers coordinate onto these molecular clusters. Also in our process, isostealate-modified oxo-alkoxide clusters may have formed during the initial stage because the water content is very low. Further continuous addition of water from the hydrous nitrogen atmosphere causes the oxide growth to proceed. Complex formation between the isostearate modifiers and oxide products probably continued to occur during the oxide growth process because of the gradual water addition. This would be a reason for the formation of the titania-based nanocomposite with organic modifiers.

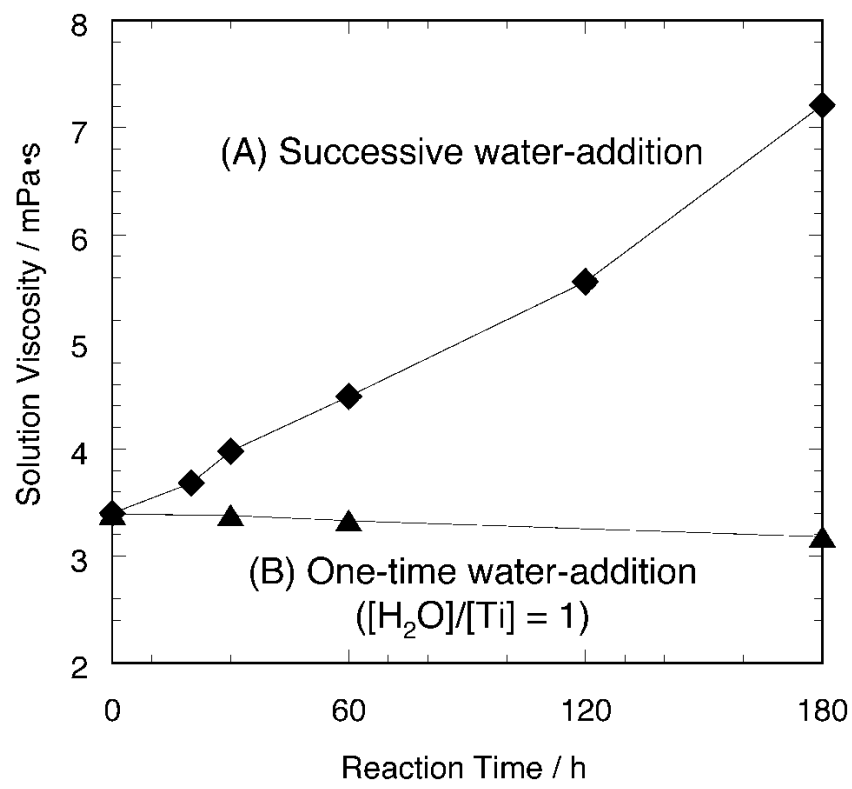

FIG. 2. Time-course of the solution viscosity and its dependence on the method of adding water. 


\section{Effect of the method of adding water on oxide growth}

In the sol-gel reaction, water addition is required to start the hydrolysis of the alkoxide. We tried two ways of adding water, and the reaction was monitored by measuring solution viscosity because oxide growth in the solgel reaction can be monitored by the change in solution viscosity. ${ }^{19,20}$

When the water was successively added by continuous bubbling of the hydrous nitrogen gas, the solution viscosity increased as the reaction time advanced [Fig. 2(A)] to form a clear sol. The oxide growth probably proceeded as the reaction time progressed without causing any phase separation. However, when water was added to the solution at all at once at the beginning, a homogeneous viscous sol was not formed regardless of the amount of added water. In the case of high water content, the ratio $\left[\mathrm{H}_{2} \mathrm{O}\right] /[\mathrm{Ti}] \geqslant 1.5$, a turbid gel was rapidly formed and separated from the solution phase. Sanchez and Ribot $^{3}$ indicated that the hydrolysis and condensation reactions of acac-modified titanium alkoxide were governed by the hydrolysis ratio $\left(\left[\mathrm{H}_{2} \mathrm{O}\right] /[\mathrm{Ti}]\right)$ and more "condensed species" were obtained as it increased. Similar condensed products may have formed also in our case by the large amount of water, leading to phase separation. In contrast, an obvious change was not observed in the case of less water addition. For example, no increase in solution viscosity was observed [Fig. 2(B)] for the case of low water ratio $\left(\left[\mathrm{H}_{2} \mathrm{O}\right] /[\mathrm{Ti}]=1\right)$. The results suggest that oxide growth scarcely proceeded with the reaction time. The same holds for the case with less water addition, $\left[\mathrm{H}_{2} \mathrm{O}\right] /[\mathrm{Ti}]<1$. Viscous sol was not obtained by one-time water addition even if the amount of added water was varied. The results suggest that the oxide growth proceeded with the reaction time in the case of the successive water-addition process with the hydrous nitrogen gas, while it hardly progressed in the case of the one-time water-addition process. Thus, successive water addition is required for sufficient oxide growth without phase separation in this system.

\section{Effect of the salt catalyst on the dimensionality of the resultant products}

A transparent viscous sol was obtained using $n$ hexylammonium isostearate as a salt catalyst. SEM observation was conducted to reveal whether twodimensional polymerization took place. After drying a diluted solution of the sol, SEM observation was conducted to reveal the morphology of the products in solutions. Two-dimensional sheets were clearly observed [Fig. 3(a)], indicating the successful two-dimensional polymerization. The sheets were very thin, on the order of a nanometer. As will be mentioned in the next section, the $x$-ray diffraction profile for the titania/isostearate nanocomposite [Fig. 4(A)] showed a diffraction peak with $d=1.83 \mathrm{~nm}$. All these observations support the formation of a two-dimensional sheet. Characteristic IR absorption bands at 1428 and $1533 \mathrm{~cm}^{-1}$ due to the $\mathrm{COO}^{-}$ stretching of the titania/carboxylate complex ${ }^{19}$ were observed for the sol after drying at $120{ }^{\circ} \mathrm{C}$. Isostearate ions

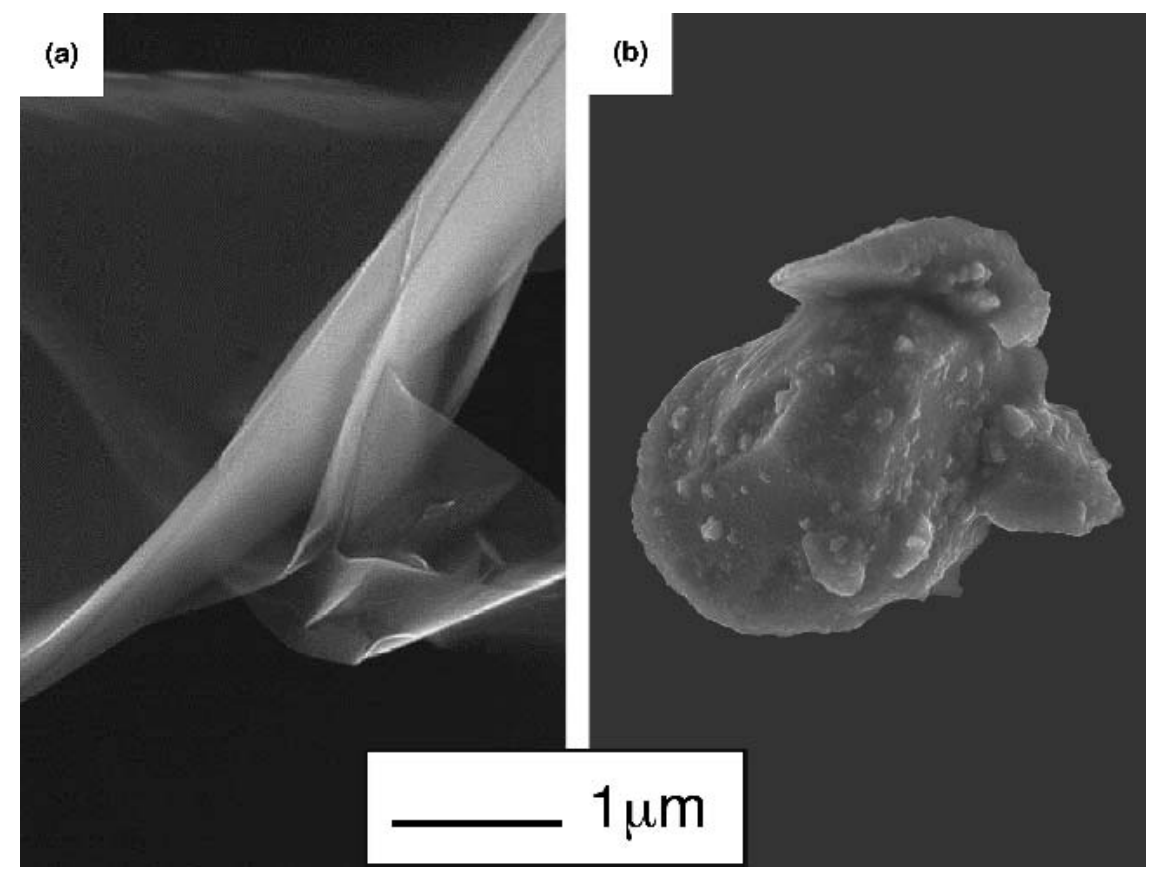

FIG. 3. Scanning electron micrographs of the products in the sol prepared (a) with and (b) without $n$-hexylammonium isostearate used as a salt catalyst. Samples were dried under vacuum at room temperature. 


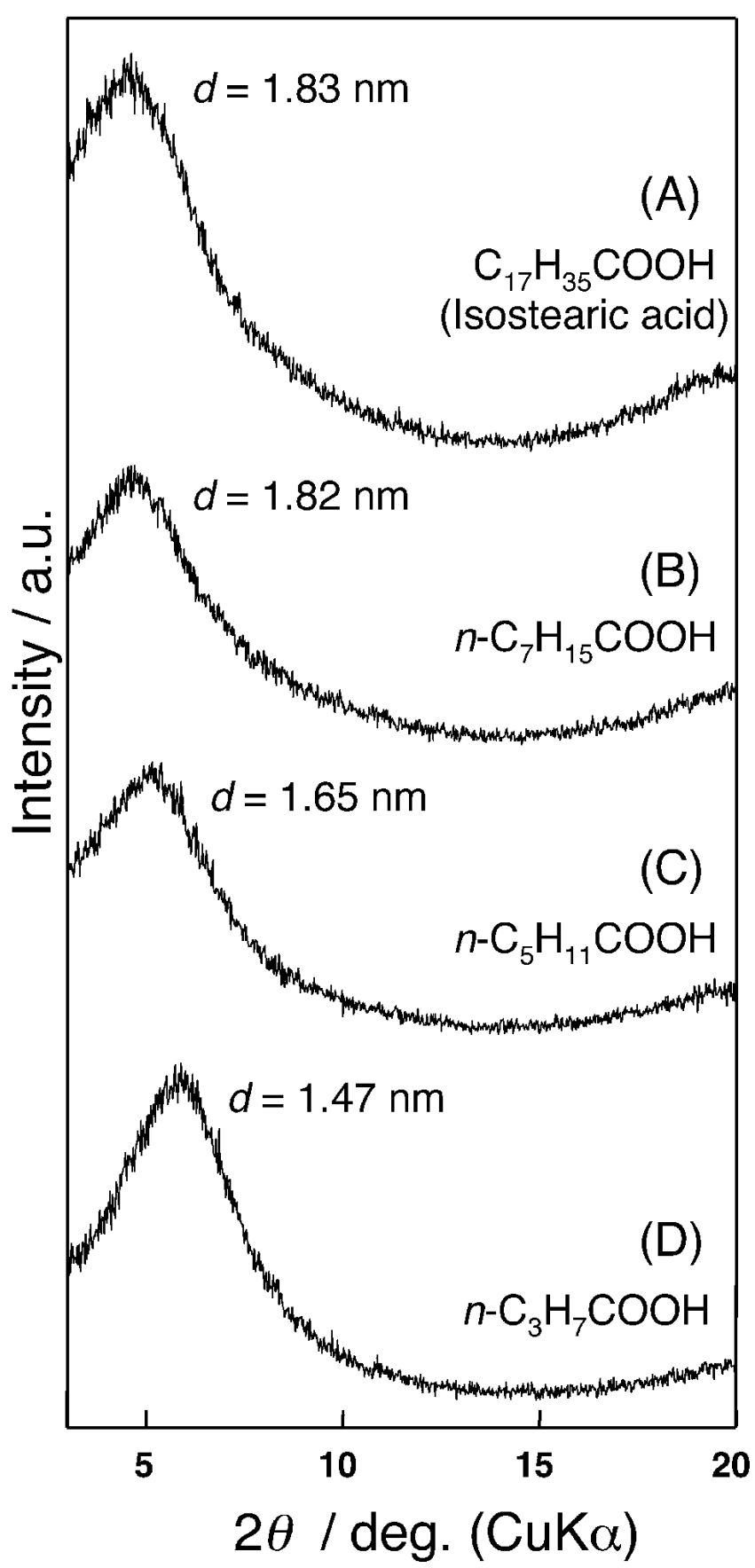

FIG. 4. XRD profiles of titania/carboxylate nanocomposites obtained by casting the sol on glass substrates. Samples were dried at $80^{\circ} \mathrm{C}$. The incorporated carboxylic acids and the $d$ values for the diffraction peaks are indicated in the figure.

would coordinate on the surface of the two-dimensional titania sheets. Because an isostearate ion has a long alkyl chain, the sheets would be stabilized in a hydrophobic solvent solution by the coordination with such carboxylates. ${ }^{22}$

Without using a salt catalyst, the solution became turbid with precipitation. Only bulky particles of about $2-\mu \mathrm{m}$ diameter were obtained [Fig. 3(b)]. Although the hydrolysis was decelerated by the hydrophobic solvent and gradual water-addition procedure, three-dimensional growth would take place. This indicates that the polycondensation was slower than the hydrolysis because of the absence of the salt catalyst; namely, the hydrolysis proceeded to a large degree before polycondensation occurred, which makes the three-dimensional growth dominant. Thus, not only the deceleration of the hydrolysis but also acceleration of polycondensation by the addition of a salt catalyst is required in this system to obtain titania sheets formed by two-dimensional growth.

\section{E. Formation of layer structure and its dependence on the length of carboxylic acids}

The $\mathrm{x}$-ray diffraction pattern for the titania/isosetarate nanocomposite was obtained by casting and drying the sol on a glass [Fig. 4(A)]. A diffraction peak with $d=$ $1.83 \mathrm{~nm}$ was observed. This pattern was ascribed to a layer structure with the basal spacing of the $d$ value. When titanium alkoxide was modified with other carboxylic acids (n-octanoic acid, $n$-hexanoic acid, and $n$ butyric acid) instead of isostearic acid, the basal spacing changed with the variety of the carboxylic acids [Figs. 4(B)-4(D)]. To estimate the long-axis length of used carboxylic acids, these were calculated using a semiempirical molecular dynamics program (MM2 in Chem3D, Cambridge Soft, MA), taking van der Waals radii into consideration (Fig. 5). The basal spacing of the layer structure depended on the length of the carboxylic acid, and almost the same basal spacing was observed for each case using isostearic acid and $n$-octanoic acid, the longaxis lengths of which are similar. The layer structure was probably constructed by the self-assembly of carboxylates coordinating on the titania sheet surfaces.

The diffraction peaks were not observed for the sol before drying. This is because the sol contained a substantial amount of solvents before drying, and ordering of the layers was not attained. Only after solvent evaporation were the layers stacked in an orderly manner to form the layered nanocomposite. To assemble titania/organic nanocomposites, solvent removal and hydrophobic interaction between the organic species would be necessary. The stacking of layers is usually hampered in the presence of a hydrophobic solvent. The long alkyl chains in a hydrophobic solvent cannot interact well because of the high affinity of the hydrophobic solvent for the long alkyl chains.

\section{F. Preparation of self-standing film of layered titania/isostearate nanocomposite}

Using the viscous clear sol obtained with the isostearate-modified titanium alkoxide and a salt catalyst ( $n$-hexylammonium isostearate), a flexible and transparent self-standing film was formed on a water surface. The floating sol gradually coagulated on the water with slight 


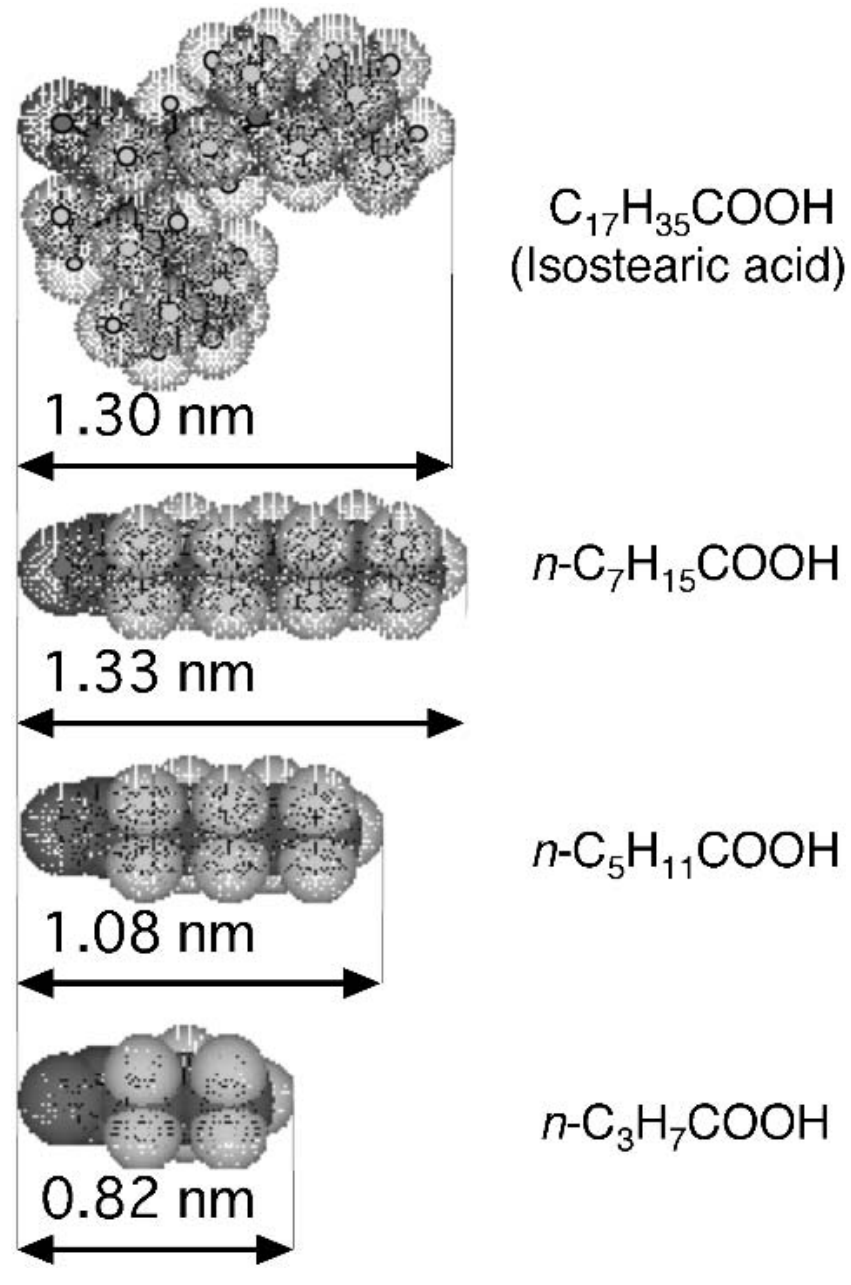

FIG. 5. Long-axis lengths for carboxylic acid molecules calculated by a semiempirical molecular dynamics program.

shrinkage and oozing of the solvent to form a film. The formed film was pulled up from the water surface and dried to evaporate the remaining solvent. The thickness of the obtained film was estimated at dozens of $\mu \mathrm{m}$. Figure 6 shows the UV-vis transmission curve for the self-standing film. The film was transparent (about 75\%) in the visible-light region $(>350 \mathrm{~nm})$. Figure 7 shows the TEM image for the powder obtained by grinding the film. The stacking of the sheets, and their edges, are observed. This indicates that the obtained film was constructed by the aggregation of titania sheets. These sheets were so thin that a sheet can be seen through the sheet in front of it. The thickness of the sheet is possibly on the order of a nanometer. Since the thickness was smaller than the wavelength of the visible light, the film was highly transparent, and it allows the light to pass through without scattering. ${ }^{14}$ On the other hand, this film cut the UV light off sharply in the range below about $350 \mathrm{~nm}$, as shown Fig. 6. Titanium oxide is a kind of photo-semiconducting oxide material, and the value of the absorption edge for the obtained film is assignable to

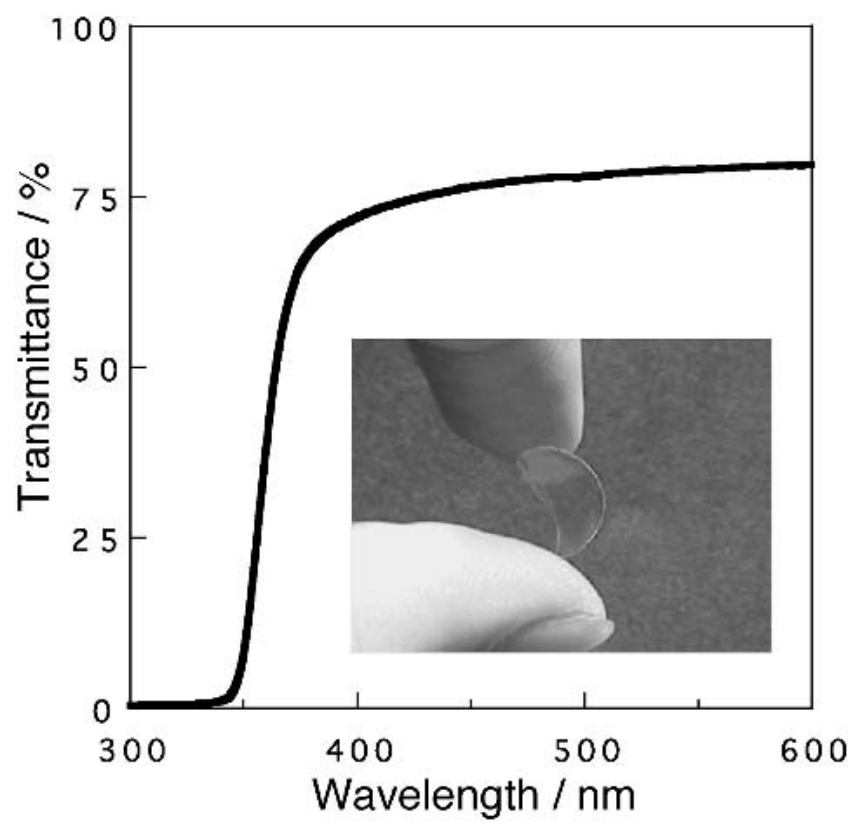

FIG. 6. Transmission spectrum for the self-standing film prepared from the sol containing titania/isostearate nanocomposites. (Inset) A photograph of the obtained self-standing film.

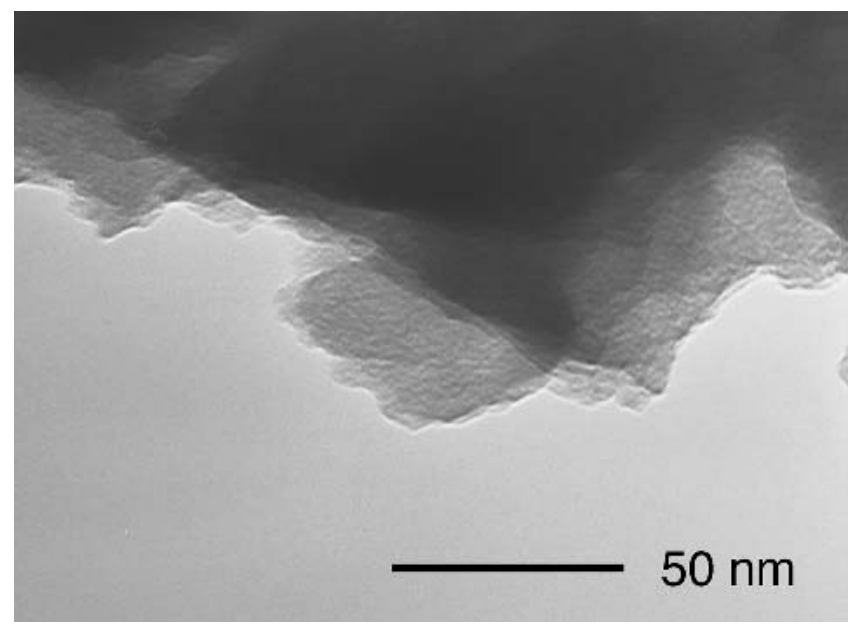

FIG. 7. Transmission electron micrograph of the self-standing film prepared from the sol containing titania/isostearate nanocomposites. The sample was ground to powder and dispersed with methanol for the observation.

a charge-transfer band of titanium oxide. Most of the UV light would be absorbed by the titania sheets, which constitute the obtained film.

A diffraction peak with $d=2.20 \mathrm{~nm}$ was observed for this film (Fig. 8). The self-standing film also has an ordered layer structure constructed by the stacking of titania sheets. The $d$ value was slightly larger, and the peak width was narrower than that for the dried sol formed on a glass plate subjected to x-ray diffraction. The reason for the larger basal spacing and better peak shape for the self-standing film is not clear; however, 


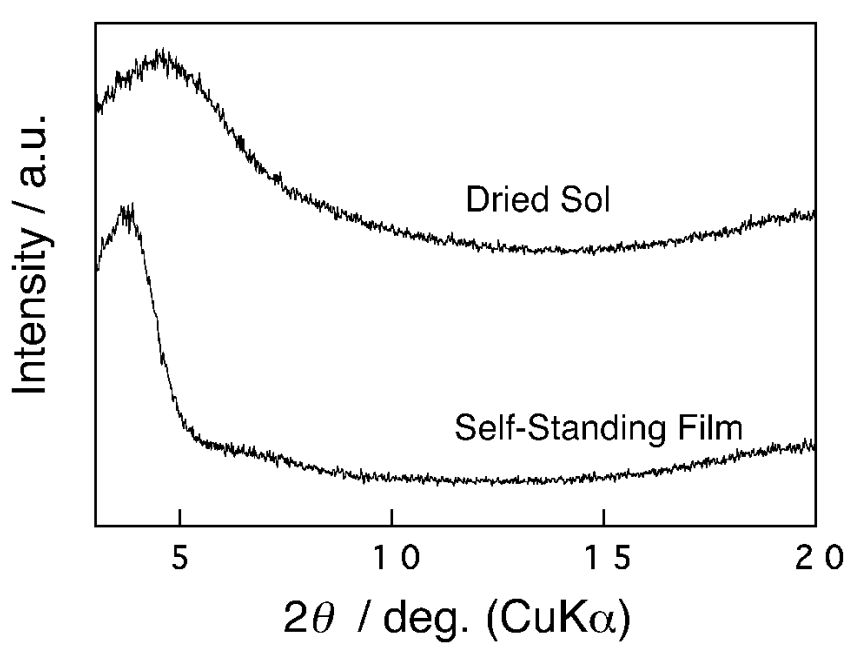

FIG. 8. XRD profiles of the sol containing titania/isostearate nanocomposites and the self-standing film obtained from the same sol. Both samples were dried at $80{ }^{\circ} \mathrm{C}$.

they probably occur because the titania/organic nanocomposites formed on water were much more ordered due to hydrophobic interaction between the alkyl chains in the carboxylates at the interface of the sol and water.

\section{G. Dependence of film-formability on the amount of added isostearic acid}

Table I summarizes the state of the obtained sol and the formation of self-standing films for different amounts of isostearic acid in the titanium tetraisopropoxide solution. For the low content of isostearic acid ([isostearic acid $] /[\mathrm{Ti}]=0,0.25)$, the resulting solution became turbid with precipitation. A self-standing film could not be obtained from these turbid solutions. Three-dimensional growth caused by rapid hydrolysis would have occurred because of an insufficient amount of isostearic acid. The control of the reactivity of titanium alkoxide has been achieved through the addition of complexing ligands, ${ }^{3,13,24,25}$ and the coordination of carboxylic acid is also known to restrict the hydrolysis of the titanium alkoxide and the dimension of oxide growth. ${ }^{19}$ The added isostearic acid would act not only as a structural director but also as a hydrolysis inhibitor.

Film-formable clear sol was obtained when the ratio

TABLE I. Dependence of the amount of added isostearic acid on the state of the resultant solution and the film-formability.

\begin{tabular}{ccc}
\hline \hline [sostearic acid]/[Ti] & $\begin{array}{c}\text { State of the resultant } \\
\text { solution }\end{array}$ & Film-formability \\
\hline 0 & Precipitation & No \\
0.25 & Precipitation & No \\
0.50 & Clear Sol & Yes \\
0.75 & Clear Sol & No \\
1.0 & Clear Sol & No \\
\hline \hline
\end{tabular}

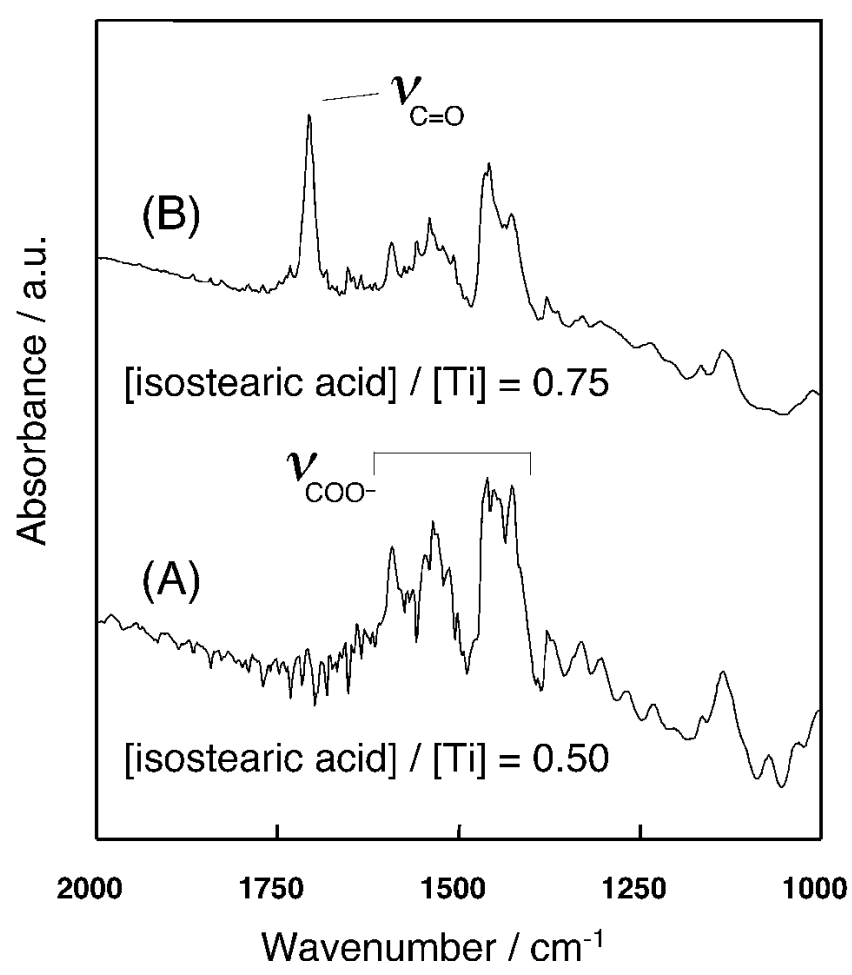

FIG. 9. IR absorption spectra of the resulting sol containing titania/ isostearate nanocomposites and its dependence on the amount of added isostearic acid. The ratios [isostearic acid]/[Ti] are shown in the figure.

[isostearic acid]/[Ti] was 0.5 . The IR spectra of the solution containing both isostearic acid and titanium tetraisopropoxide showed characteristic adsorption bands at 1426,1458 , and $1540 \mathrm{~cm}^{-1}$, which were attributable to $\mathrm{COO}^{-}$stretching bands for the bidentaite coordination of the Ti(IV)-carboxylate complex ${ }^{19}$ [Fig. 9(A)]. The coordination of isostearate should have restricted the hydrolysis reaction so that a sheetlike structure was formed by the lower dimensional growth.

In the case of more isostearic acid content, the ratio [isostearic acid] $/[\mathrm{Ti}] \geqslant 0.75$, floated sol was not concentrated on the water surface, and a self-standing film was not formed in spite of the formation of the clear sol. The IR spectra of this sol ([isostearic acid]/[Ti] $=0.75$ ) exhibited an additional absorption peak at $1707 \mathrm{~cm}^{-1}$ [Fig. 9(B)]. This peak is due to the carbonyl band ( $\mathrm{C}=\mathrm{O}$ stretching), which was observed for the solution containing only isostearic acid [Fig. 1(A)]. This indicates that the non-coordinating isostearic acid exists in this sol. Such excess isostearic acid in sol would block the concentration of the sol on the water surface and inhibit the formation of a self-standing film.

\section{CONCLUSIONS}

In summary, a flexible and transparent self-standing film of titania/isostearate nanocomposite was obtained by floating a sol on water. The sol was prepared by a 
hydrophobic sol-gel process, in which a titanium tetraisopropoxide/isostearate complex (a precursor), $n$ hexylammonium isostearate (catalyst), and $o$-xylene (solvent) were used. The sol thus obtained was poured onto water, and after the removal of the solvent, the ordered layer structure was constructed, yielding a self-standing film.

Because the obtained film was optically clear, a new application may be expected in the field of optics and optoelectronics. There is a possibility that a new type of photosemiconducting material will be obtained by intercalating photofunctional guests into the titania interlayer. It may be used as a precursor of novel photocatalysts, although both processes for the removal of organic modifiers and for the crystallization of titania sheets would be necessary. The development of such a synthetic approach would pave the way for a new application field for titania.

\section{ACKNOWLEDGMENT}

This work was supported by Research Fellowships of the Japan Society for the Promotion of Science for Young Scientists.

\section{REFERENCES}

1. C. Sanchez, B. Lebeau, F. Chaput, and J-P. Boilot: Optical properties of functional hybrid organic-inorganic nanocomposites. Adv. Mater. 15, 1969 (2003).

2. J. Wen and G.L. Wilkes: Organic/inorganic hybrid network materials by the sol-gel approach. Chem. Mater. 8, 1667 (1996).

3. C. Sanchez and F. Ribot: Design of hybrid organic-inorganic materials synthesize via sol-gel chemistry. New J. Chem. 18, 1007 (1994).

4. K. Sakata and T. Kunitake: A multilayered film of an ultrathin siloxane network. Chem. Commun. 504 (1990).

5. M. Ogawa: Formation of novel oriented transparent films of layered silica-surfactant nanocomposites. J. Am. Chem. Soc. 116, 7941 (1994).

6. M. Ogawa: Preparation of layered silica-dialkyldimethylammonium bromid nanocomposite. Langmuir 13, 1853 (1997).

7. A. Sellinger, P.M. Weiss, A. Nguyen, Y. Lu, R.A. Assink, W. Gong, and C.J. Brinker: Continuous self-assembly of organicinorganic nanocomposite coatings that mimic nacre. Nature 394, 256 (1998).

8. Y. Lu, R. Gangull, C.A. Drewien, M.T. Anderson, C.J. Brinker, W. Gong, Y. Guo, H. Soyez, B. Dunn, M.H. Huang, and J.I. Zink: Continuous formation of supported cubic and hexagonal mesoporous films by sol-gel dip-coating. Nature 389, 364 (1997).
9. M. Ogawa and T. Kikuchi: Preparation of self-standing transparent films of silica-surfactant mesostructured materials and the conversion of porous silica films. Adv. Mater. 10, 1077 (1998).

10. M. Ogawa, H. Ishikawa, and T. Kikuchi: Preparation of transparent mesoporous silica films by a rapid solvent evaporation method. J. Mater. Chem. 8, 1783 (1998).

11. H. Yamashita, S. Kawasaki, Y. Ichihashi, M. Harada, M. Takiuchi, and M. Anpo: Characterization of titanium-silicon binary oxide catalysts prepared by the sol-gel method and their photocatalytic reactivity for the liquid-phase oxidation of 1-octanol. J. Phys. Chem. B 102, 5870 (1998).

12. M. Aizawa, Y. Nosaka, and N. Fujii: FTIR liquid attenuated total refraction study of $\mathrm{TiO}_{2}-\mathrm{SiO}_{2}$ sol-gel reaction. J. Non-Cryst. Solids 128, 77 (1991).

13. J. Livage and C. Sanchz: Sol-gel chemistry. J. Non-Cryst. Solids 145, 11 (1992).

14. M. Kallala, C. Sanchez, and B. Cabane: Structures if inorganic polymers in sol-gel processes based on titanium oxide. Phys. Rev. E 48, 3692 (1993).

15. M. Ogawa, K. Ikeue, and M. Anpo: Transparent Self-standing films of titanium-containing nanoporous silica. Chem. Mater. 13, 2900 (2001).

16. Q. Xu and M.A. Anderson: Sol-gel route to synthesis of microporous ceramic membranes: Preparation and characterization of microporous $\mathrm{TiO}_{2}$ and $\mathrm{ZrO}_{2}$ xerogel. J. Am. Ceram. Soc. 77, 1939 (1994).

17. I. Moriguchi, H. Maeda, Y. Teraoka, and S. Kagawa: Preparation of $\mathrm{TiO}_{2}$ ultrathin film by newly developed two-dimensional solgel process. J. Am. Chem. Soc. 117, 1139 (1995).

18. I. Moriguchi, H. Maeda, Y. Teraoka, and S. Kagawa: Preparation of a $\mathrm{TiO}_{2}$ nanoparticulate film using a two-dimensional sol-gel process. Chem. Mater. 9, 1050 (1997).

19. Y. Murakami, T. Matsumoto, and Y. Takasu: Salt catalysts containing basic anions and acidic cations for the sol-gel process of titanium alkoxide: Controlling the kinetics and dimensionality of the resultant titanium oxide. J. Phys. Chem. B 103, 1836 (1999).

20. T. Matsumoto, Y. Murakami, and Y. Takasu: Size control of titanium oxide sheets by regulating catalysis in a catalytic sol-gel process and their UV absorption properties. J. Phys. Chem. B 104, 1916 (2000).

21. D. Ganguli and D. Kundu: Preparation of amorphous $\mathrm{ZrO}_{2}$ coationg from metal-organic solutions. J. Mater. Sci. Lett. 3, 503 (1984).

22. T. Nakamura, Y. Murakami, and Y. Takasu: Synthesis of transparent and oil-dispersible planar titania. J. Jpn. Soc. Col. Mater. 72, 760 (1999).

23. T. Matsumoto, Y. Murakami, and Y. Takasu: Preparation of a UV-absorbed transparent monolithic titanium oxide gel by the catalytic sol-gel process with a phenanthroline hydrochloride catalyst, Chem. Lett. 177 (1999).

24. C. Sanchz, J. Livage, M. Henry, and F. Babonneau: Chemical modification of alkoxide precursor. J. Non-Cryst. Solids 100, 65 (1988).

25. J. Blanchard, F. Ribot, C. Sanchz, P-V. Bellot, and A. Trokiner: Structual characterization of titanium-oxo-polymers synthesized in the presence of protons or complexing ligands as inhibitors. J. Non-Cryst. Solids 265, 83 (2000). 